\title{
Modeling particulate matter emissions during mineral loading process under weak wind simulation
}

\author{
Xiaochun Zhang ${ }^{\text {a,b }}$, Weiping Chen ${ }^{\text {a,* }}$, Chun Ma ${ }^{\text {b }}$, Shuifen Zhan ${ }^{\text {b }}$ \\ a State Key Laboratory of Urban and Regional Ecology, Research Center for Eco-Environmental Sciences, Chinese Academy of Sciences, Beijing 100085, PR China \\ b Tianjin Research Institute for Water Transport Engineering, Ministry of Transport, Tianjin 300456, PR China
}

\section{H I G H L I G H T S}

- There are limitations in applying the empirical models to predict PM emission factors for mineral loading under weak winds.

- We modeled particulate matter emission factor of mineral loading processes under weak winds.

- A new approach of logistical function was developed and tested.

- New model focused on the effect of wind velocity.

- The new model works well for simulating stacker mineral loading processes.

\section{A R T I C L E I N F O}

\section{Article history:}

Received 6 August 2012

Received in revised form 9 January 2013

Accepted 14 January 2013

Available online 17 February 2013

\section{Keywords:}

Particulate matter emission

Mathematical model

Particles

Mineral loading

Wind tunnel

\begin{abstract}
A B S T R A C T
The quantification of particulate matter emissions from mineral handling is an important problem for the quantification of global emissions on industrial sites. Mineral particulate matter emissions could adversely impact environmental quality in mining regions, transport regions, and even on a global scale. Mineral loading is an important process contributing to mineral particulate matter emissions, especially under weak wind conditions. Mathematical models are effective ways to evaluate particulate matter emissions during the mineral loading process. The currently used empirical models based on the form of a power function do not predict particulate matter emissions accurately under weak wind conditions. At low particulate matter emissions, the models overestimated, and at high particulate matter emissions, the models underestimated emission factors. We conducted wind tunnel experiments to evaluate the particulate matter emission factors for the mineral loading process. A new approach based on the mathematical form of a logistical function was developed and tested. It provided a realistic depiction of the particulate matter emissions during the mineral loading process, accounting for fractions of fine mineral particles, dropping height, and wind velocity.
\end{abstract}

(c) 2013 Elsevier B.V. All rights reserved.

\section{Introduction}

Vast amounts of minerals are loaded, transported, unloaded, and stockpiled daily around the world (Betzer et al., 1988; Rosing, 2008; Vasconcelos and McKenzie, 2009; Goix et al., 2011; Csavina et al., 2012). Atmospheric particulate matter is one of the important factors influencing climate forcing and the atmospheric environment. (Tegen et al., 1996; Beavington et al., 2004; Baker and Jickells, 2006; IPCC, 2007; Santacatalina et al., 2010). The stacker, a material handling tool, is commonly employed for bulk loading at mines and transportation hubs (Edgar, 1983; FAM, 2012). While the transported mineral is not a pollutant and does not necessarily represent an environmental

\footnotetext{
* Corresponding author. Tel.: +8610 62843981; fax: +861062918177. E-mail address: wpchen@rcees.ac.cn (W. Chen).
}

pollution problem, fugitive mineral particulate matter resulting from loading and unloading may pose potential health hazards to exposed individuals nearby (Uno et al., 2009; Gautam et al., 2012). The extent of the potential harmful effects is dependent on the physical nature of the particles and on ambient conditions (Castranova et al., 1985; Brabin et al., 1994; Whicker et al., 2006; Bergstrom et al., 2011; Goix et al., 2011). The particulate matter emission factor (E), in $\mathrm{kg}$ of airborne fine particles released per ton of mineral, depicts the degrees of air pollution from various particulate matter emission sources (US EPA, 2006; Surendra et al., 2010). Mathematically, E is conceptualized as a function of the variables defining the loading conditions, and equation parameters are empirically determined (Wainwright and Mulligan, 2003). Measuring the $E$ factor is challenging, however, as the loading conditions shift constantly.

Several empirical models for calculating particulate matter emission factors under mineral loading processes have been proposed. The major models for a typical mineral, coal, are listed as follows (Cowherd and Cuscino, 1977; Wang et al., 1985; MOT, 2011; US EPA, 2006). 
In Cowherd and Cuscino (1977), the particulate matter emission factor, $E(\mathrm{~kg} / \mathrm{ton})$, is calculated as:

$\left.E=k_{1}(0.0009)(s / 5) v / 2.2\right)(H / 3.0)(M 2)^{-2}$

where $k_{1}$ is a constant; $s$ is the silt content (\%); $v$ is wind velocity $(\mathrm{m} / \mathrm{s})$; $H$ is drop height (m); and $M$ is moisture content of the coal (\%). According to Wang et al. (1985), $E$ is calculated as:

$E=k_{2} v^{0.3} e^{-0.82 \mathrm{M}}$

where $k_{2}$ is a constant varying with ambient conditions, such as atmospheric temperature and atmospheric humidity, and $e$ is the base of natural logarithms. Other parameters of Eq. (2) have been previously defined. The JTJ226 formula by MOT (2011) defined $E$ as:

$E=0.03 v^{1.6} H e^{-r}$

where $r$ is a coefficient. In the AP42 empirical formula put forward by the US EPA (2006), $E$ was calculated as

$E=k_{4} 0.0016(v / 2.2)^{1.3}(M / 2)^{-1.4}$

where $k_{4}$ is a particle size multiplier.

Typically, empirical models perform well within the parameter ranges of wind velocities and ratios of fine vs. coarse particles for which they are designed. However, when parameters exceed the ranges from which models are derived, the mathematical equations fail in their predictability (Ghose, 2007). Wind velocity (v) is by far the single most important parameter in the prediction. The particulate matter emission factor $(E)$ is linked to wind velocity $(v)$ through a power function (i.e. $A v^{n}$, where $A$ and $n$ are constant parameters), characterizing its contribution with the power exponential constant, $n$. The wind velocity in this case is simply a model-fitting parameter and does not connote any mechanistic and physical significance. Taking the AP42 model (Eq. (4)) as an example, $E$ is a power function of wind velocity with exponential constant $n=1.3$. If wind velocity is greater than $\sqrt[n]{1 / A}$, the particulate matter emission factor $(E)$ will exceed $1000 \mathrm{~kg} /$ ton. That means, even if all the minerals are blown away, the observed $E$ still cannot meet the calculated results. Although widely accepted, there are limitations in applying the empirical models to predict particulate matter emission factors for mineral loading, especially under weak wind conditions, which tend to be ignored (Golitsyn et al., 2003). It is imperative to revisit the mathematical descriptions making sure the predicted particulate matter emission factor is realistic under weak winds.

We hypothesized that in characterizing the particulate matter emission factor, the wind velocity, $v$, would dynamically change according to logistic curves. The objective of this research is to develop a logisticbased particulate matter emission factor model, and to elucidate the role of wind velocity on the particulate matter emission factor under weak wind simulation. Experimental data from wind tunnel experiments were employed to evaluate the emission factor for mineral particulate matter under different wind velocities and particle distributions.

\section{Material and methods}

\subsection{Model development}

In loading, fine and coarse mineral particles after dropping off the loader tend to separate due to gravity and the air buoyancy (Gaudin et al., 1931; Wyslouzil, 2009). In the presence of wind, more of the fine particles are separated from the mainstream. They are easily carried away by wind (Etkin, 1980; Katalambula and Gupta, 2009; Wang et al., 2012). This portion of the fine particles is referred to hereafter as "carry-able particles".
Given a mineral material with total mass of $m_{0}$ in which the proportion of fine particles is $p$ with unit 1 and the proportion of carry-able particles of the fine particle fraction is $\varepsilon$ in \%, the mass of carry-able particles $m_{p}$ (same unit as $m_{0}$ ) is given as:

$m_{p}=\varepsilon \cdot p \cdot m_{0}$

Under the influence of wind velocity $v$ in $\mathrm{m} / \mathrm{s}$, the particulate matter emission factor for the mineral material is $E(v)$ in \% and mass of carried away particles $m_{e}(v)$ (same unit as $m_{0}$ ) is:

$m_{e}(v)=E \cdot m_{0}$

where $m_{e}(v) \leq m_{p}$. The remaining portion of the carry-able fine particles $R_{p}$ with unit 1 is:

$R_{p}(v)=1-m_{e}(v) / m_{p}$.

The mass of carry-able particles would increase with the wind velocity. Under an incremental wind velocity of $\Delta v \mathrm{~m} / \mathrm{s}$, there will be an incremental proportion of carried away particles $\Delta m_{e}(v) / m_{e}(v)$, so that the incremental rate with respect to wind velocity is proportional to the remaining portion of the fine particles, $R_{p}(v)$ :

$\left(\Delta m_{e}(v) / m_{e}(v)\right) / \Delta v=\alpha R_{p}(v)$

where $\alpha$ is the proportional coefficient. The increased mass of carried away particles with respect to increased wind velocity $\Delta m_{e}(v) / \Delta v$ is:

$\Delta m_{e}(v) / \Delta v=\alpha m_{e}(v) R_{p}(v)$.

Combining Eqs. (7) and (9), the differential form of Eq. (9) is:

$d m_{e}(v) / d v=\alpha m_{e}(v)\left(1-m_{e}(v) / m_{p}\right)$.

Let

$\gamma=\alpha(\tau)$

where $\tau$ is a unit conversion factor, which is used to balance the units of the model.

Eq. (10) is reorganized by consolidating parameters:

$d m_{e}(v) / d v=\gamma m_{e}(v)\left(m_{p}-m_{e}(v)\right) / m_{p}$

and then separating the dependent and independent variables:

$\left(1 / m_{e}(v)+1 /\left(m_{p}-m_{e}(v)\right)\right) d m_{e}(v)=\gamma d v$

Integrating Eq. (13) results in:

$\ln \left(m_{e}(v)\right)-\ln \left(m_{p}-m_{e}(v)\right)=\gamma v+c$

where $c$ is a constant.

General solution $m_{e}(v)$ (same unit as $\left.m_{0}\right)$ is:

$m_{e}(v)=m_{p} /\left(1+e^{-(\gamma v+c)}\right)$.

Combining with Eqs. (5), (6), and (15), the particulate matter emission factor is

$E=\varepsilon p /\left(e^{-(\gamma v+c)}+1\right)$

where $E$ is the particulate matter emission factor with unit \%o; $p$ is proportion of fine particles with unit $1 ; v$ is wind velocity with unit $\mathrm{m} / \mathrm{s} ; \varepsilon$ is the proportion of carry-able particles in fine particles with 


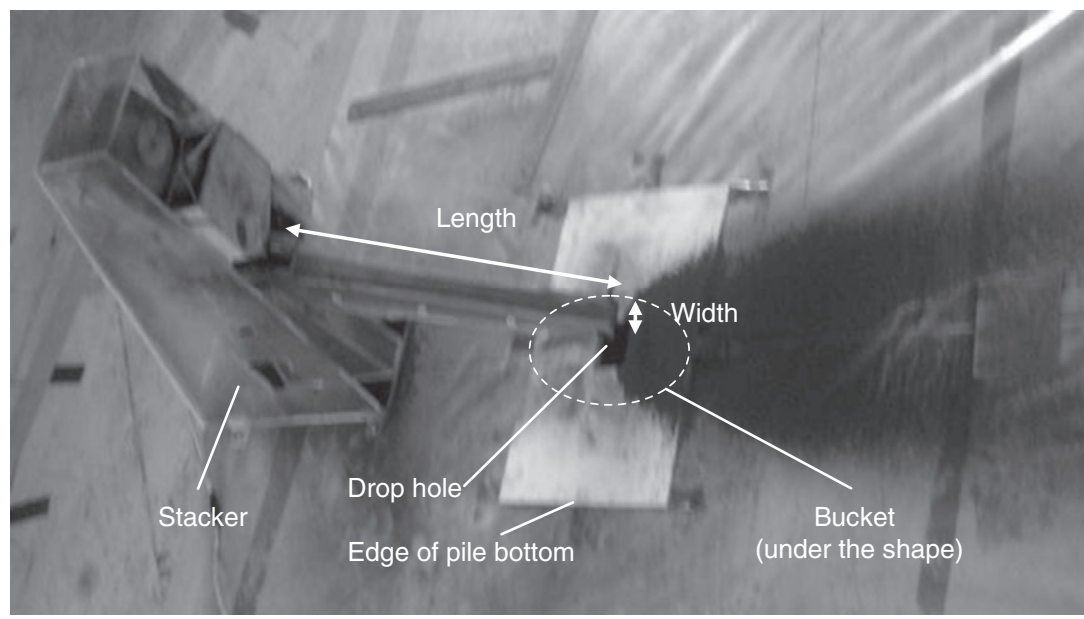

Fig. 1. Schematic diagram of models in wind tunnel test.

unit \%; $\gamma$ with unit $\mathrm{s} / \mathrm{m}$ and $c$ with unit 1 are constants characteristic of loading and particles. Eq. (16) denotes the logistic particulate matter emission factor model.

\subsection{Wind tunnel test}

Mineral particulate matter emission measurement experiments were conducted at an atmospheric boundary layer wind tunnel facility located in Peking University in Beijing, China (Fig. 1). The open-circuit wind tunnel was designed to simulate environmental aerodynamics including particle flows. It has a straight line suction design with a working section of $32 \mathrm{~m}$ in length, $2 \mathrm{~m}$ in height and $6 \mathrm{~m}^{2}$ in cross-sectional area. The roof of the wind tunnel was adjusted to eliminate the pressure gradient. The facility extends $6 \mathrm{~m}$ above a smooth bed surface. Boundary layers were developed under the requirement suggested by Irwin (1981) and Snyder (1981). The length to height ratio of 16 exceeds the minimum requirement of 5 suggested by White and Mounla (1991) for natural development of a boundary layer. Wind velocity is sampled using a DISA hot wire anemometer (Denmark Inc.), which had been calibrated in DISA's jet wind tunnel (White and Mounla, 1991; McKenna, 2003). More illustration can be found in Zhang et al. (2012).

For a common large stacker, the conveyor belt is approximately $40 \mathrm{~m}$ long and $1.4 \mathrm{~m}$ wide with a drop height of $1 \mathrm{~m}$. For the experimental simulation, a 1:100 scale model stacker was constructed. The model was $400 \mathrm{~mm}$ in length, $14 \mathrm{~mm}$ in width and had $10 \mathrm{~mm}$ of drop height. The scaled down stacker was fitted into the wind tunnel and during a test, the stacker operated continuously. To avoid the effects of mineral material accumulation, a small bucket was installed to collect the falling mineral material.

In the experiment, the material used was coal, which is considered a typical mineral (Medina et al., 2010; Yao and Sun, 2012). Samples which were selected for testing are three typical coals (humidity content of 3.2\%) which were shipped across China (Table 1). The tested samples consisted of only the fraction that passed through a sieve

Table 1

Particle size distributions of coal samples.

\begin{tabular}{lllll}
\hline Category & Particle size range & \multicolumn{4}{l}{ Particle fraction of sample } \\
\cline { 3 - 5 } & & I & II & III \\
\hline $\begin{array}{c}\text { Fine particles } \\
\left(m_{p}\right)\end{array}$ & $<250 \mu \mathrm{m}$ & 0.2368 & 0.1825 & 0.0583 \\
$\begin{array}{c}\text { Coarse particles } \\
\left(m_{0}-m_{p}\right)\end{array}$ & 250 to $1000 \mu \mathrm{m}$ & 0.7632 & 0.8175 & 0.9417 \\
\hline
\end{tabular}

with opening of $1000 \mu \mathrm{m}$. The fine fractions (i.e. $m_{p}$ ) of mineral samples were $0.2368,0.1825$, and 0.0583 , respectively. For testing, the mineral samples were dried at $40{ }^{\circ} \mathrm{C}$ for approximately $12 \mathrm{~h}$ until the humidity content approached 0 . The dried samples were then wetted with an ultrasonic humidifier to raise the humidity contents to a uniform $3.2 \%$.

Prior to starting up, the mass of mineral sample, $m_{c 1}$, mass of model stacker, $m_{s 1}$ and mass of bucket, $m_{b 1}$ were recorded. Wind velocities were set at 1.5, 2.0, 3.0, 4.0, 5.0, 6.0, and $7.0 \mathrm{~m} / \mathrm{s}$. When wind velocity reached the preset level, the model stacker was turned on to run the mineral dropping operation for $15 \mathrm{~min}$. The mass of remaining matter and model stacker, $m_{\mathrm{cs} 2}$, and the mass of the receptacle bucket and mineral collected, $m_{c b 2}$ (including the mineral particles within the edge of the pile bottom) were recorded.

\subsection{Data analysis}

By mass balance, the emitted particulate matter mass of an experiment, $m_{d}$, is obtained:

$m_{d}=m_{c 1}+m_{s 1}+m_{b 1}-m_{c s 2}-m_{c b 2}$

and emission factor in the experiment $E_{\text {experiment }}$ is:

$E_{\text {experiment }}=m_{d} / m_{c 1}$.

Assuming that the mass of mineral matter dropped is $M$ per unit drop height and the mass of emitted particulate matter diffused under wind velocity of $v$ is $m$ per unit distance, the emission factor $E$ for the mineral matter dropped at a height of $H$ is then:

$E=m L / M H$

where $L$ is the diffusion distance of emitted particulate matter such that:

$L=v \sqrt{2 H / a}$

where $a$ is the acceleration of the material dropping. The emission factor $E$ can be rewritten as:

$E=(1 / \sqrt{H})(\sqrt{2} m v / \sqrt{a} M)$.

Therefore under the given testing conditions $E \propto 1 / \sqrt{H}$. The scale of the stacker model was 1:100 in the wind tunnel experiment. The dropping height in the field using a full scale stacker would be 100 times higher than that in the experiment. The relation between the 
emission factor in the field $E_{\text {field }}$ and emission factor in the experiment Experiment proportionally is:

$E_{\text {field }}=E_{\text {experiment }} / 10$.

The reported particulate matter emission factors refer to those of the full scale equipment used in the field.

\subsection{Model analysis}

The emission factor models were fitted using experimental data by the NLFit Process (Nonlinear Curve Fit Analysis), Origin Pro v8.5. The analyses include: (1) identify the best-fit empirical particulate matter emission factor model for the mineral matter loading process; (2) validate the efficacy of the logistic particulate matter emission factor model that we have developed; (3) compare logistic with empirical particulate matter emission models to obtain the best one for estimating the particulate matter emission factor from mineral matter loading between the logistic and empirical models; and (4) analyze the flexibility of the model formulation to match model features with the mineral loading process analysis.

Statistical parameters including coefficient of model fitting $\left(R^{2}\right)$, root mean square error (RMSE) and Bias value $(B)$ were employed to evaluate the model fitting.

\section{Results and discussion}

\subsection{Particulate matter emission factor estimated by existing empirical models}

The ability of four existing empirical models, i.e. Eqs. (1) through (4), in estimating the particulate matter emission factors was tested based on data obtained in the wind tunnel experiments. For model fitting, the data from three samples, representing mineral matter of varying particle size distributions, were pooled (Table 2). Among the four empirical models, the JTJ226 model (Eq. (3)) appeared to fit the experimental data better than the remaining three, based on the outcomes of statistical parameters for model testing.

The JTJ226 model (Eq. (3)) appeared to overestimate the particulate matter emission factor at low and medium wind velocities from 2 to $5.5 \mathrm{~m} / \mathrm{s}$ and underestimate the particulate matter emission factor when wind velocities exceeded $5.5 \mathrm{~m} / \mathrm{s}$ (Fig. 2). The particle size distribution characteristics of minerals further influenced the outcomes. Based on the statistical parameters for the model fitting, the predictive power of the model was in inverse proportion to the fraction of fine particles in the mineral matter. For example in the worst case scenario, for mineral matter sample II, the particulate matter emission factors estimated by the JTJ226 model (Eq. (3)) were 2 to 4 times higher than their respective measured particulate matter emission factors when wind velocities ranged from 1.50 to $5.00 \mathrm{~m} / \mathrm{s}$, and about 20\% lower than their respective measured particulate matter emission factors when wind velocities exceeded $6.00 \mathrm{~m} / \mathrm{s}$. For sample III, the fine particle fraction of which was $58.3 \%$, the nonlinear regression fit for the model was significant at $p<0.05$ with $R^{2}=0.855$, $R M S E=0.047 \%$ o and $B=0.016 \%$ 。 (Fig. 2). For sample II where the fine particle fraction was $182.5 \%$, the resulting

Table 2

Comparative statistics for particulate matter emission factor models of material loading.

\begin{tabular}{lrlll}
\hline $\begin{array}{l}\text { Particulate matter } \\
\text { emission factor }\end{array}$ & $R^{2}$ & $\begin{array}{l}R M S E \\
(\%)\end{array}$ & $\begin{array}{l}B \\
(\%)\end{array}$ & Reference \\
\hline $\begin{array}{c}E=k_{1}(0.0009)(\mathrm{s} / 5) \cdot \\
(v / 2.2)(H / 3.0)(M / 2)^{-2}\end{array}$ & -0.838 & 0.374 & 0.076 & Cowherd and Cuscino (1977) \\
$E=k_{2} v^{0.3} e^{-0.82 M}$ & -0.830 & 0.464 & 0.045 & Wang et al. (1985) \\
$E=0.03 v^{1.6} H e^{-r}$ & 0.220 & 0.325 & 0.061 & MOT (2011) \\
$E=k_{4} 0.0016(v / 2.2)^{1.3 .}$ & -0.119 & 0.346 & 0.069 & US EPA (2006) \\
$(M / 2)^{-1.4}$ & & & & \\
\hline
\end{tabular}
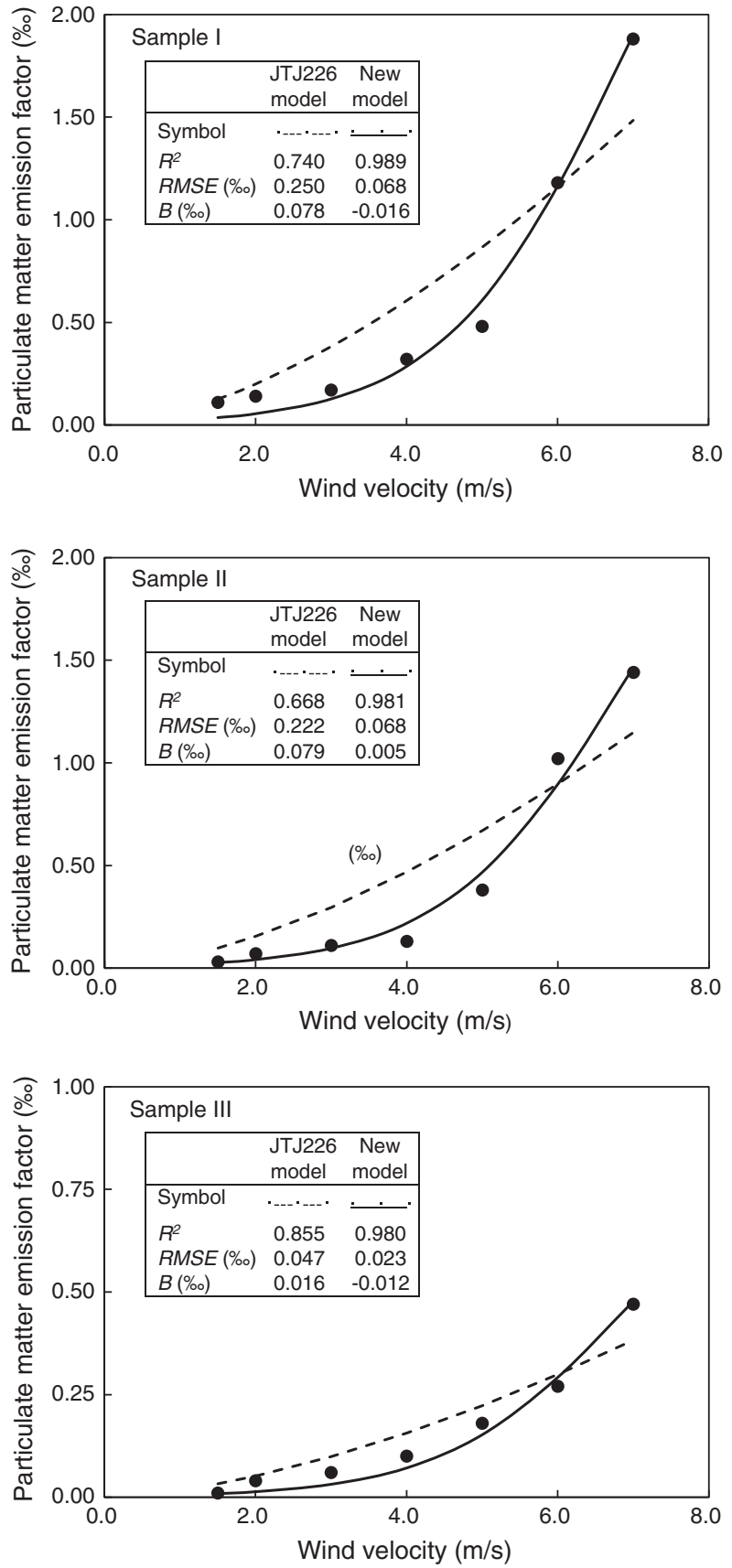

Fig. 2. Particulate matter emission factor of coal loading, fitting to the JTJ226 model and new model.

model in this case did not fit as well with $R^{2}=0.668$, RMSE $=0.222 \%$ 。 and $B=0.079 \%$ o (Fig. 2). These results succinctly illustrated that the ability of empirical models for particulate matter emission factor to estimate outcomes is specific to the mineral loading conditions. What is found to be suitable for minerals with low fine particle fraction might not be appropriate in estimating the particulate matter emission factor $(E)$ in other situations. The particle mechanics had a compensatory effect on the resulting statistical parameters.

In all, the empirical models were able to predict the particulate matter emission factors under limited conditions. They did not perform correctly under weak wind conditions. Therefore, the empirical models were not ideal to estimate the particulate matter emission factor for the mineral matter loading process. 


\subsection{Estimating particulate matter emission factor with logistic model}

Based on the logistic analyses for the particulate matter emission process, the particulate matter emission factor, $E$, is estimated by Eq. (16), which is restated in the following:

$E=\varepsilon p /\left(e^{-(\gamma v+c)}+1\right)$

where $E$ is the particulate matter emission factor with unit in \%; $p$ is the unit-less fraction of fine particles ( 0 to 1 ); $v$ is wind velocity in $\mathrm{m} / \mathrm{s} ; \varepsilon$ is the proportion of carry-able particles in fine particle fraction in \%; $\gamma$ in $\mathrm{s} / \mathrm{m}$ and $c$ (unit-less) are constants characteristic of mineral matter loading and particle sizes. In Eq. (16), there are three parameters, namely $\varepsilon, \gamma$ and $c$, and two independent variables, namely $p$ and $v$. The first step was to obtain the model's structure parameters $\gamma$ and $c$ employing the nonlinear regression in which wind velocity $v$ and proportion of fine particles $p$ were independent variables. The constants characterizing loading and particle sizes, $\gamma$ and $c$, were 0.86 and -5.88 , respectively, with the regression significant at $\mathrm{p}<0.01, R^{2}=0.664, R M S E=0.279 \%$, $B=-0.011 \%$. In the process of nonlinear regression, the parameter $\varepsilon$ was not significant.

To obtain parameter $\varepsilon$ which characterized the carry-able particles in the fine particle portion of mineral matter, we engaged in multiple regression analysis with wind velocity, $v$, and proportion of fine particles, $p$, as independent variables and in this case the particle sizes of the minerals were distinguished as three separate data sets for model fitting. The statistical parameters of the model fitting showed satisfactory outcomes (Fig. 2) and $\varepsilon$ for mineral samples I, II, and III of the difference of fine vs. coarse particle ratios were $15.00,15.01$, and $15.30 \%$, respectively. The parameter $\varepsilon$ in Eq. (16) might simply be represented by the mean, $15.10 \%$. The logistic-function-based particulate matter emission factor of Eq. (16) turned out to more realistically represent the experimental data. It no longer exhibited the inherent wind velocity-induced swing in over- and under-estimations that characterized the empirical models for the particulate matter emission factor (Fig. 2). Take mineral sample I for example, the experimental data fitted Eq. (16) with $R^{2}=0.99, B=-0.016 \%$ o and $R M S E=0.068 \%$. At low wind velocities of $v<5.00 \mathrm{~m} / \mathrm{s}$, the logistic-model-estimated particulate matter emission factors were with 0.5 to 1.2 times those of the experimental measurements. Beyond that, the estimated and measured particulate matter emission factors were essentially in agreement. In all the experimental data the logistic function fitted the model well. The regression was significant at $p<0.01$, and $B \leq 0.016 \%$, RMSE $\leq 0.068 \%$, and $R^{2} \geq 0.980$.

\subsection{Logistic vs. empirical models}

Advantages of the logistic model over the empirical models in estimating mineral particulate matter emission factors during the loading process may be further illustrated by data shown in Fig. 3, where the estimated vs. measured particulate matter emission factors of the logistic model (Eq. (16)) and the best-performing empirical model, JTJ226 (Eq. (3)), are compared side by side. The logistic model provides accurate estimated particulate matter emission factors throughout the entire particulate matter emission factor range. With the empirical model JTJ226 (Eq. (3)), the particulate matter emission factors were overestimated at the low emission end and underestimated at the high emission end.

In a perfect prediction, $\mathrm{Y}=\mathrm{X}+0$ in Fig. 3 . When the data points of Fig. 3 were fitted to a linear regression of $Y=a X+b$, the Eq. parameters were $\mathrm{a}=1.01$ and $\mathrm{b}=0.01\left(R^{2}=0.99\right)$ for the logistic model and $\mathrm{a}=0.76$ and $\mathrm{b}=0.16\left(R^{2}=0.88\right)$ for empirical model JTJ226 (Fig. 3 ). When the data points of Fig. 3 were fitted to a linear regression of $\mathrm{Y}=\mathrm{a}^{\prime} \mathrm{X}$, the Eq. parameter $\mathrm{a}^{\prime}=0.999$ and 0.908 for the logistic and JTJ226 models $\left(R^{2}=0.99\right.$ and 0.80$)$, respectively. Either way, the Eq.
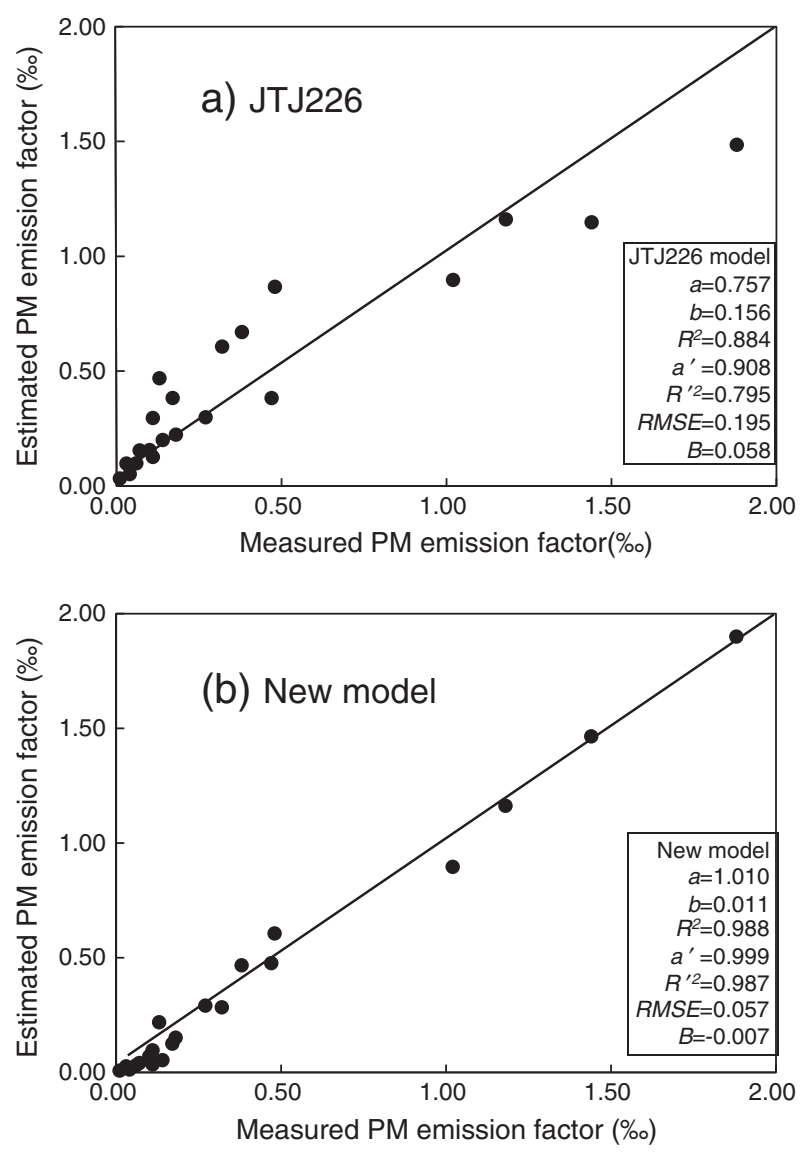

Note: $a$ and $b$ are the coefficients of the regression line $y($ est. $)=a x($ meas. $)+b ; a^{\prime}$ is

the coefficients of the regression line $y($ est. $)=a^{\prime} x$ (meas.).

Fig. 3. Estimated particulate matter (PM) emission factor vs. measured PM emission factor using JTJ226 model and new model.

parameters of the linear regressions associated with the logistic model realistically depicted a perfect prediction of $\mathrm{Y}=\mathrm{X}$.

\subsection{Flexibility of model formulation}

During the mineral matter loading process, fine and coarse mineral particles were separated not only vertically via the wind movement but also horizontally under the convective air and upward impulse (Katalambula and Gupta, 2009; Wang et al., 2012). In other words, there will be particulate matter emitted even if the wind velocity is zero. In addition, fine particles and coarse particles could not be entirely

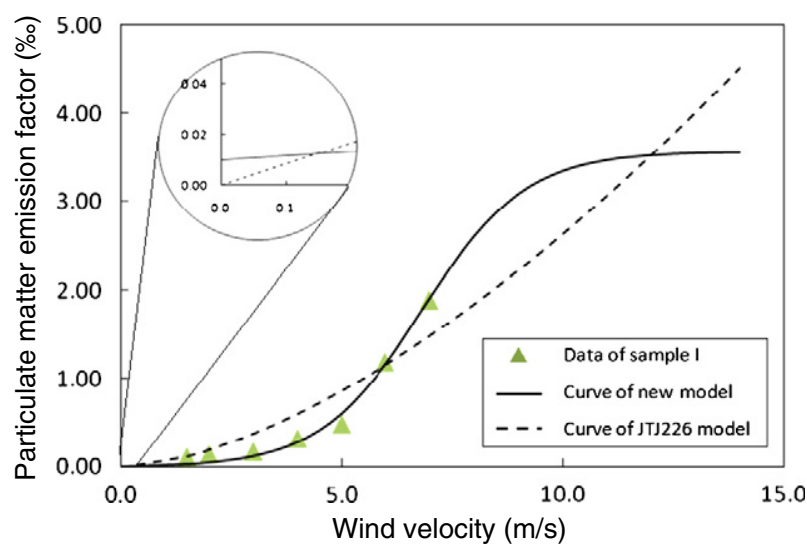

Fig. 4. Curves shapes of JTJ226 model and new model, using data of sample I. 
separated, because dropping time and dropping height were limited. The mineral contains fixed amounts of fine particles beyond which no more mineral particulate matter may be emitted. The particulate matter emission factor would reach an upper boundary limited by the content of fine particles in the mineral beyond which, the particulate matter emission factor remains constant no matter what wind velocities are.

When there is no wind, i.e. $v=0$, the JTJ226 empirical model (Eq. (3)) would predict the particulate matter emission factor, $E=0$; and for the logistic model, the estimated particulate matter emission factor, $E=\varepsilon p /\left(e^{-c}+1\right)$. When the wind velocity increases, the particulate matter emission factor calculated by the JTJ 226 empirical model approaches the infinite $(+\infty)$. Employing the logistic model, the estimated particulate matter emission factor would rise to approach an upper limit, $\varepsilon p$. Using mineral sample I as an example, the phenomena are graphically illustrated in Fig. 4.

\section{Conclusions}

Fugitive mineral particulate matter from mineral loading could cause serious atmospheric environmental issues on regional and global scales. We illustrated that the empirical models currently used in evaluating the mineral particulate matter emission factors in loading processes are deficient, especially under weak winds. For minerals with high fine particle fractions, the empirical models overestimated the particulate matter emission factor at the low emission end and underestimated them at the high emission end. Subsequently, a new approach was used to derive a logistic function based predictive model such that $E=\varepsilon p /\left(e^{-(\gamma v+c)}+1\right)$, where $E$ was particulate matter emission factor, $p$ was proportion of fine particles, $v$ was wind velocity, and $\varepsilon, \gamma$ and $c$ were constants characteristic of loading and particles. The test results showed that the new model provided realistic depictions of particulate matter emissions during mineral loading processes.

\section{Acknowledgments}

The authors thank Professor Albert L. Page from the University of California, Riverside for language help. We also thank the editor and reviewers for their valuable comments on this article.

\section{References}

Baker A, Jickells T. Mineral particle size as a control on aerosol iron solubility. Geophys Res Lett 2006;33:L17608.

Beavington F, Cawse PA, Wakenshaw A. Comparative studies of atmospheric trace elements: improvements in air quality near a copper smelter. Sci Total Environ 2004;332:39-49.

Bergstrom C, Shirai J, Kissel J. Particle size distributions, size concentration relationships, and adherence to hands of selected geologic media derived from mining, smelting and quarrying activities. Sci Total Environ 2011:409:4247-56.

Betzer PR, Carder KL, Duce RA. Long-range transport of giant mineral aerosol particles. Nature 1988;336:568-71.

Brabin B, Smith M, Milligan P. Respiratory morbidity in Merseyside schoolchildren exposed to coal dust and air pollution. Arch Dis Child 1994;70(4):305-12.

Castranova V, Bowman L, Reasor MJ. The response of rat alveolar macrophages to chronic inhalation of coal dust and/or diesel exhaust. Environ Res 1985;36(2): 405-19.
Cowherd C, Cuscino T. Fugitive emissions evaluation, MRI-4343-L. Kansas City, MO: Midwest Research Institute; 1977.

Csavina J, Field J, Taylor M, et al. A review on the importance of metals and metalloids in atmospheric dust and aerosol from mining operations. Sci Total Environ 2012;433: $58-73$.

Edgar TF. Coal processing and pollution control. Houston, Texas: Gulf Publishing Company; 1983. p. 1-579.

EPA, Environmental Protection Agency of US. Compilation of air pollutant emission factors, AP-42. Research Triangle Park, NC. AP-42 section 13.2.4 aggregate handling and storage piles6th ed.; 2006.

Etkin B. Method and apparatus for particle classification. US Pantent, PN 4213852, 1980.

FAM, Förderanlagen Magdeburg. Förderanlagen Magdeburg's Stackers; 2012 [http:// www.bulk-materials-handling.info/english/Products/Stockyard\%2520systems/Stackers/ index.html].

Gaudin A, Grob J, Henderson H. Effect of particle size in flotation, technical publication no. 414. New York, NY, USA: AIME; 1931.

Gautam S, Patra AK, Prusty BK. Opencast mines: a subject to major concern for human health. Int Res J Geol Min 2012;2(2):25-31.

Ghose MK. Opencast coal mining in India: assessing air pollutant emission rates. Environ Qual Manag 2007;17(1):35-51.

Goix S, Point D, Oliva P, Polve M, Duprey JL, Mazurek H, et al. Influence of source distribution and geochemical composition of aerosols on children exposure in the large polymetallic mining region of the Bolivian Altiplano. Sci Total Environ 2011;412-413: 170-84.

IPCC. IPCC IV climate change 2007: the physical science basis. New York: Cambridge University Press; 2007. p. 1-940.

Irwin H. The design of spires for wind simulation. J Wind Eng Ind Aerod 1981;7:361-6.

Katalambula H, Gupta R. Low-grade coals: a review of some prospective upgrading technologies. Energy Fuel 2009;23(7):3392-405.

McKenna NC. Effects of temperature and humidity upon the entrainment of sedimentary particles by wind. Bound-Lay Meteorol 2003;108:61-89.

Medina A, Gamero P, Querol X, et al. Fly ash from a Mexican mineral coal I: mineralogical and chemical characterization. J Hazard Mater 2010;181(1-3):82-90.

MOT, Ministry of Transport of PR China. The environment impact assessment specifications for port construction project, JTJ-226. Beijing. JTJ-226 section 3.3.3.1 coal handling and storage piles of port; 2011.

Golitsyn GS, Granberg IG, Andronova AV, et al. Investigation of boundary layer fine structure in arid regions. Water Air Soil Pollut 2003;3:245-57.

Rosing MT. Earth science: on the evolution of minerals. Nature 2008;456:456-8.

Santacatalina M, Reche C, Minguillon MC, Escrig A, Sanfelix V, Carratala A, et al. Impact of fugitive emissions in ambient PM levels and composition: a case study in Southeast Spain. Sci Total Environ 2010;408:4999-5009.

Snyder WH. Guideline for fluid modeling of atmospheric diffusion, EPA-600/8-81-009. Research Triangle Park, NC: US EPA; 1981.

Surendra R, Adhikari GR, Singh TN. Development of emission factors for quantification of blasting dust at surface coal mines. J Environ Prot 2010;1:346-61.

Tegen I, Andrew A, Fung I. The influence on climate forcing of mineral aerosols from disturbed soils. Nature 1996;380:419-22.

Uno I, Eguchi K, Yumimoto K, et al. Asian dust transported one full circuit around the globe. Nat Geosci 2009;2:557-60.

Vasconcelos C, McKenzie JA. The descent of minerals. Science 2009;323(5911):218-9.

Wainwright J, Mulligan M. Environmental modelling: finding simplicity in complexity. Chichester: John Wiley and Sons; 2003. p. 1-430.

Wang B, Qi M, Xu Y, Quan G. A study of release and dispersion of coal dust caused by handling coal. J Wuhan Inst Water Trans Engine 1985;30(4):41-50.

Wang H, Chen X, Bai Y, Guo C, Zhang L. Application of dissolved air flotation on separation of waste plastics ABS and PS. Waste Manage 2012;32(7):297-305.

Whicker JJ, Pinder JE, Breshears DD, Eberhart CF. From dust to dose: effects of forest disturbance on increased inhalation exposure. Sci Total Environ 2006;368:2-3.

White BR, Mounla H. Froude number effect on wind tunnel saltation. Acta Mech Suppl 1991;1:145-57.

Wyslouzil HE. The production of high grade iron ore concentrates using flotation columns; 2009 [http://en-ca.eriez.com/Products/Markets/mineralflotation].

Yao Y, Sun H. A novel silica alumina-based backfill material composed of coal refuse and fly ash. J Hazard Mater 2012;213-214:71-82.

Zhang XC, Chen W, Ma C, et al. Modeling the effect of humidity on the threshold friction velocity of coal particles. Atmos Environ 2012;56:154-60. 